DOI: 10.1515/ausfm-2015-0033

\title{
Poetry in Transmedial Perspective: Rethinking Intermedial Literary Studies in the Digital Age
}

\author{
Heike Schaefer \\ University of Konstanz (Germany) \\ E-mail: heike.schaefer@uni-konstanz.de
}

\begin{abstract}
In the digital age, literary practice proliferates across different media platforms. Contemporary literary texts are written, circulated and read in a variety of media, ranging from traditional print formats to online environments. This essay explores the implications that the transmedial dispersal of literary culture has for intermedial literary studies. If literature no longer functions as a unified single medium (if it ever did) but unfolds in a multiplicity of media, concepts central to intermediality studies, such as media specificity, media boundaries and media change, have to be reconsidered. Taking as its test case the adaptation of E. E. Cummings's experimental poetry in Alison Clifford's new media artwork The Sweet Old Etcetera as well as in YouTube clips, the essay argues for a reconceptualization of contemporary literature as a transmedial configuration or network. Rather than think of literature as a single self-contained medium that engages in intermedial exchange and competition with other media, such as film or music, we can better understand how literature operates and develops in the digital age if we recognize the medial heterogeneity and transmedial distribution of literary practice.
\end{abstract}

Keywords: intermedial literary studies, transmedia culture, digital poetry, YouTube, E. E. Cummings, adaptation.

To begin with the obvious: digital technologies have altered our practices of communication and representation. They have modified our aesthetic expectations and changed the ways in which literary texts are composed, distributed and read today. Since the emergence of digital media has transformed literary culture, the premises and practice of intermedial literary studies have also started to change. Literary scholars have begun to consider the interactions between literature and new media, examining the new types of texts and the new 
forms of representation, publication and reception that digital culture spawns. To expand literary studies in order to include new genres, such as hypertexts, blogs or digital poetry, is a promising first step. Yet it seems to me that we need to go further if we want to comprehend how digital culture is reconfiguring literary culture. It is my contention that we need to develop a new understanding of literature as a medium, or, to put it another way, of the mediality of literature.

I would like to propose the following shift in critical perspective: first, it seems to me that we have a better chance at understanding how literature participates in contemporary media culture if we stop thinking of literature as a single, clearly bounded medium and, instead, focus our analysis on the different medial constellations in which literature is created and experienced today. In other words, instead of discussing intermediality solely with regard to the interactions between literature and other media, such as painting or photography, we could also comprehend it as a constitutive element within the literary field itself. Since transmedial exchange and distribution are a generative force within and a prime characteristic of contemporary literary culture, our intermedial inquiry should include the study of the media of literature. Second, if we think of literature as making use of, materializing in, or extending across different media, we need a concept that helps us conceive of the nexus that the different media of literature form. The network model provides such a concept.

This paper will focus on the first of these claims and seek to demonstrate the advantage of conceptualizing contemporary literature as a transmedial practice and configuration by offering an exemplary reading of a printed poem and its digital adaptations - namely, E. E. Cummings's poem $l(a$, which was originally published in his 1958 collection 95 Poems, and its remediation in Alison Clifford's online artwork The Sweet Old Etcetera (2006) as well as in YouTube videos.

\section{The Printed Text: Linguistic and Visual Systems of Signification in E. E. Cummings's Poetry}

I begin with a short analysis of $l(a$, one of the five poems by Cummings that Clifford reworks in her digital project.

l(a
le
af 


\author{
fa \\ 11 \\ s) \\ one \\ 1 \\ iness
}

The poem signifies primarily through the typographical arrangement of letters, words and punctuation marks on the page. It is clearly a visually rather than sound oriented text. If we listened to a reading of the poem without contemplating its visual design, we would lose a significant dimension of its meaning (cf. Kidder 1979, 282). The poem's layout is unconventional and calls on the reader to actively engage with it. Coming across the poem for the first time, we may not know, for instance, how to make sense of the letters that make up its first line. Does the first letter function as a letter or as a numeral, is this an l or a I? The ambiguity of the poem's very first mark initiates a play with signifiers that continues throughout the poem. The next lines confront the reader with groups of one to five letters that are arranged vertically on the page. None of the clusters makes sense semantically except for the word one in the third to last line. The reader is prompted to play with the letters. Reading the poem becomes an exercise in reshuffling the signs into a meaningful order.

A reading strategy that proves helpful in this situation is to reverse the direction of the typographical layout. By rearranging the lines horizontally, we get the line:

$l(a$ le af $\mathrm{f}$ all s) one $\mathrm{l}$ iness.

This way, the combination of several letters into words suggests itself more easily:

l(a leaf falls) one 1 iness.

If we take out the parenthetical expression, we receive:

(a leaf falls) $l$ one $l$ iness.

In this construction, the poem's initial sign turns out to be the letter 1 rather than the roman numeral one, I. We can contract the remaining separate letter clusters into one word:

(a leaf falls) loneliness.

This way, we are presented with an image and a sentiment. The connection between the metaphor's vehicle and tenor has to be forged by the reader through 
association. The interpretation depends on an imaginative jump, reminiscent of the sudden conceptual twist characteristic of haikus. The poem represents the feeling of being alone and isolated. The single falling leaf - and by extension the autumnal landscape, the drawing back of the life force of the plants into their roots - symbolizes a sense of diminishment, of things and perhaps even of life coming to an end, of retreat, solitude and loneliness.

Both the theme and the metaphor of the poem are fairly conventional. Numerous other poems have used the image of falling leaves to express sadness about being alone, about aging and dying. Rainer Maria Rilke's poem Autumn Day (1902) is a well-known case in point. It concludes with the lines: "Whoever is alone now will remain so for a long time, / will stay up, read, write long letters, / and wander the avenues, up and down, / restlessly, while the leaves are blowing." If we place Cummings's work in this poetic tradition, the most innovative element of his poem is its form. The fragmentation of the words through line breaks, the insertion of a parenthetical phrase into a word, the layout of the poem on the page - all these formal aspects of the poem strain against the conventions of English grammar and seek to break out of the mold of literary tradition. The visual arrangement of the letters on the page is semantically motivated, however: it does not serve to dissolve but to "modify and enhance" the meaning of the words (Heusser 1995, 19).

Unlike a concrete poem, pattern poem or calligram (Bray 2012, 298-302), the poem's overall shape does not form a clearly defined visual image. ${ }^{1}$ The poem does not function as an icon. Nevertheless, its visual form serves to reinforce the poem's coherence and enriches its processes of signification. The fragmentation of the words through line breaks creates an unusual vertical orientation that allows the shape of the poem to visually suggest the downward movement of the leaf. The extremely short lines of the poem force the reader's gaze into a steep vertical plunge - creating an analogy to the ways our eyes would track the falling of a leaf. The effect is reinforced by the use of parenthesis (Landles 2001, 39). The slightly curved shape of the bracket resembles a leaf, and the change from open to closed parenthesis in the course of the poem suggests the spiralling downward motion of the leaf, its turning over in the air. The sequence of the segmented letter pairs also suggests this spinning movement: the "af" in the third line becomes "fa" in the fourth. The leaf has flipped over (Landles 2001, 39). At the same time,

1 As several critics have pointed out, the poem's unusual, elongated and slender shape does recall the letter 1 though, which is the initial letter of both leaf and loneliness, the two words that the poem correlates. 
the poem's fragmentation of meaningful semantic units also conveys a severing of union and offers a typographical analogy for the disintegration of association or community that may create the sense of separation and isolation that transforms solitude or oneness into loneliness (DiYanni 2003, 584). Making the most of his material - language and print - Cummings creates a complex representation of the topic - loneliness - in just four words. He combines linguistic and visual systems of signification to expand the possibilities of poetic expression.

\section{The Digital Artwork: Alison Clifford's Adaptation of Cummings's "Poempictures"}

In her online artwork The Sweet Old Etcetera (2006), Alison Clifford adapts Cummings's poetry. My analysis of her remediation will pursue these questions: how does the balance between linguistic and visual systems of signification, between text and image shift as the text is adapted to the new medium of digital art? What new strategies of representation does the digital environment enable? What ways of reading does it require? How does this change the reader's engagement with the poem and alter the relation between author, text and reader?

Clifford's web art project The Sweet Old Etcetera presents several of Cummings's poems in the form of an interactive digital environment. It combines text, image, and sound. The most striking feature is the flash animation of letters and words that the reader activates through mouse movements and by clicking on links. The moving letters coalesce into visual shapes and eventually build up into the image of a landscape composed of words [Fig. 1].

There are several ways to conceive of the relation between Clifford's artwork and Cummings's poem. For one, it is an adaptation. It remakes the original and gives us a new version of it. To ensure that the readers will be aware of this intertextual aspect of the work, the title explicitly quotes one of Cummings's poems - The Sweet Old Etcetera. By alerting the readers to the fact that they are reading an adaptation, the title encourages them to compare the two works, to read the adaptation in relation to the original and vice versa. Secondly, because Clifford's work transfers the content of one medium to another, it also constitutes an intermedial transposition (cf. Rajewsky 2005, 51). The classic example for an intermedial transposition would be a film version of a novel. The media change in Clifford's case occurs from literature to visual art, or to be more specific, from printed poem to digital artwork. And thirdly, Clifford's work presents a remediation of a printed text, in the sense of Jay Bolter's and Richard Grusin's 
study of digital culture, Remediation (1999). The new digital medium reworks the older analog medium of print. One medium represents another. All three terms can be applied to Clifford's work: adaptation, intermedial transposition, remediation. Each categorization brings a different aspect of the relation between Cummings's and Clifford's work into focus. The term adaptation highlights the fact that an original text is reissued in a different version. The term intermedial transposition stresses that a media change is involved in this adaptation. The term remediation emphasizes the refashioning of one medium in the terms of another.

In the context of intermedial literary studies, the last two terms are of particular interest since they foreground questions of mediality and media interaction. Despite their difference in perspective, the two terms imply a shared premise: both intermedial transposition and remediation suggest that we are dealing with an interaction between two distinct, self-contained media. In this view, literature constitutes a single medium - the realm to which Cummings's poetry belongs. And digital art constitutes another medium - the realm to which Clifford's work belongs. The two media do not blend but content is transferred from one medium to another. And indeed, we could say that Clifford's adaptation of Cummings's poetry entails a change in medium because it involves a shift in technological means, systems of signification and processes of communication. In terms of technology, the poems now are encoded, distributed and read on computers (cf. Funkhouser 2008). The means of transmission has changed. We access the online text through the computer's interface. The digital environment transforms both the material properties and semiotic systems of the text. We encounter the poem not in print on the page but in form of a flash website that combines language, sound, and image. The digital form also affects the communicative process because it introduces an interactive dimension into the reading process.

To highlight the media change involved in Clifford's adaptation and to posit the existence of distinct, self-contained media has the heuristic advantage that it allows us to discuss the media-specific aspects of Cummings's and Clifford's works. The comparative perspective brings into focus how each medial configuration functions and what effect it generates. Let me bear out his point by comparing the relation between text and image in the two versions and the mode of response they invite. Both works combine linguistic and visual signification to invest the text with a kinetic quality. Cummings uses typography and page design to instill the static print on the page with a "figurative equivalent" of motion (Friedman 1960, 123). He suggests the twirling, descending movement of the leaf through line breaks and the spatial arrangement of the letters and lines on the page. Cummings called his 
poems "poempictures," explaining to his editor that his "poems are essentially pictures" (quoted in Heusser 1995, 16). Yet the intermedial term is slightly misleading because the visual quality of the poem is an effect of typography, a device specific to the medium of print. Although Cummings was a painter, he never included drawings, illustrations, or pictorial elements in his poems (Heusser 1995, 17). Also, his poems rarely form patterns or shapes that would represent objects in an iconic way. Instead, Cummings employs words simultaneously as words and as images (Mahler 2010, 114). He uses them at the same time as symbolic signs that have only an arbitrary connection to their real world referent, and as graphs that may suggest a figurative analogy to an observable phenomenon (as in this case, a leaf's spiralling downward movement; Mahler 2010, 114).

Like Cummings, Clifford does not use any extraneous graphic elements in the presentation of the individual poems. In her piece, however, the letters coalesce into the shape of recognizable objects. They form a tree, hills, clouds, an entire landscape made of words. The greatest visual difference, of course, is that Clifford uses flash to animate the text. In her work, the letters literally move. Sometimes they are programmed to move automatically, sometimes they require the reader's interaction to be set in motion. The striking second half of the animation especially involves the readers in the poem's resolution. As the letters dissolve under their mouse movements and clicks and vanish from the screen, the readers may experience the anguish of a frustrated attempt at connection. This creates an experiential parallel to the sense of diminishment and loneliness that the poem expresses. ${ }^{2}$ Yet regardless of the reader's technical interaction with and emotional involvement in the poem, the sequence of the animation and the paths of the letters' movement are pre-set. The readers cannot influence, for instance, in what direction and at what speed the letters move. This delimits the readers' control over the unfolding and structure of the text. Despite the work's interactive quality, the reader never becomes a co-creator of the text, as early hypertext theory tended to claim (Morris 2006, 13).

The interactive quality of the digital text brings out the playfulness of Cummings's poetics (Clifford 2012) and this, together with a shift from the pole of the symbolic towards the iconic, makes the text more easily accessible for readers. The ludic, interactive and iconic quality of the digital text may reduce the readers' resistance to a poem that cannot be understood quickly but that requires time and effort to

2 It also demonstrates the symbolic implications of using flash software to set the poem in motion. The flash animation introduces a strong temporal quality into the text, enabling the artist to address "concepts of permanence, transience, and transition in the presentation" of the poem (Howard n.d.). 
decipher and comprehend. By breaking with the rules of grammar and by pushing poetic conventions like enjambment to an extreme, Cummings's poem confounds us. It slows down our reading process and prompts us to puzzle over and mentally reassemble its segments. In the process, it makes us take note of the material poetry is built of: typographical marks on a white page, letter, words, lines, stanzas. As Cummings proposed, "the day of the spoken lyric is past. [...] The poem which has at last taken its place does not sing itself; it builds itself, three dimensionally, gradually, subtly, in the consciousness of the experiencer" (Kennedy 1980, 128).

Clifford's work dramatizes the processuality and performativity of both text and interpretation that Cummings's comment points to. It externalizes and thus makes visible the processes of both composition and reception. As is typical for digital poetry, the sequential display of the poem defines "the stage of relationships among words and even within one single word" (Strehovec 2010, 214). Because the sequence and pacing of the animation reveal the poem's grammatical and logical structure from the beginning, readers engage with the digital text in a different way than with the printed poem. As we watch the animated poem, we first see a pair of brackets floating down the screen like a leaf; next, we observe word fragments appear in meaningful clusters and form the sentence "a leaf falls;" then, we witness the phrase become enveloped by the word loneliness. Because of the successive presentation of the poem in semantically meaningful segments, we never experience linguistic disorientation. We are never at a doubt about the grammatical and semantic correlations between the word fragments we encounter. The sequential presentation of the poem discloses the logic of the text's structure. It puts on display and makes observable the process of writing and reading the poem.

\section{Online Videos: The Adaptation of Cummings's Poem in YouTube Clips}

It comes as little surprise that the pleasure of solving the text's riddle is at the core of many of the performances and adaptations of the poem on YouTube. ${ }^{3}$ Like Clifford's piece, several clips use animation to portray the successful deciphering

3 There is a wide variety of YouTube clips that adapt or comment on Cummings's work. People film themselves reciting and interpreting the poem (Gotera; Stevens). They turn the poem into a song or instrumental musical piece that they perform (The Lyrez; Seglias; De Biasi, Lebow and Furlone). They make realistic shorts that illustrate the poem's themes (Conti; Thiery, Griffin and Kanga; Rowell and Clavette) or experimental videos that address the poem more obliquely (Munoz). Or they focus on the poem's typographical layout and present animations of its letters and words (lorianggie; ronjosiah). 
of the text. Lorianngie's e.e.cummings 1(a (2011) or Vince Gotera's Deconstructing Cummings (2009), for instance, begin by presenting the poem in the typographical arrangement of the original print version and then proceed to demonstrate how the fragments can be reassembled to form words and parenthetical expression. The two videos attest to the curiosity that the poem may incite in readers. The adaptations retain the focus on the questions posed by a reading of the printed text: what is this? How does this make sense? Like Clifford's flash work, they produce a new process-oriented question, namely: what will happen next? As in Clifford's web art, the clips' animation of the poem's letters re-enacts Cummings's composition process. Fittingly, both clips represent the semiotic medium he worked with - paper and typeface [Figs. 2-3]. The animations also dramatize and thus make available for observation the reconstructive activity that the reader has to undertake mentally in order to make sense of the poem. In this way, the YouTube adaptations, like Clifford's intermedial transposition, share the medial self-reflexivity of the printed text. They draw the viewers' attention to the materiality, organization and functioning of the poem and they become an occasion for the reader's/viewer's self-reflection.

Notwithstanding these common features, the YouTube videos also differ in crucial respect from Clifford's adaptation. Unlike the readers of Clifford's interactive work, YouTube viewers need not wonder whether they can influence the text. Like traditional film spectators, they cannot manipulate the film while viewing it. Also, the YouTube clips typically offer complete narratives that leave little room for the viewer's imaginative extrapolation. The poem's meaning is explicitly explained or realistically dramatized. Several clips show falling leaves, portray lonesome figures moving through deserted places, or feature portrait shots of sad faces (Conti; lorianngie; Munoz; Rowell and Clavette; Thiery, Griffin and Kanga). Thus, they do not confront the viewers with their interpretative choices in the same degree as the printed text or Clifford's work. Yet because YouTube functions not only as a digital archive but also as a social medium, viewers may interact with the original clips after watching the video: they may post a comment, produce a spoof or create an adaptation of their own. Their readings and performances are informed by the dynamics of the collaborative media platform, which also shape the cultural and social function of the texts they produce.

If we compare the different medial configurations in which the poem takes shape - from printed literary text to web-based digital artwork to digital videos embedded in an online archive and social media platform - significant similarities and differences emerge. My analysis aimed to show that the changes 
in technology, in transmissive channels, semiotic systems and processes of communication make it productive to conceptualize the interrelations between the poem's different versions in terms of media change. Each version of the poem is realized through media-specific processes of production, signification and reception. Examining the intermedial transpositions and remediations involved in the poem's adaptation enriches our understanding of how the texts generate meaning, how they participate in communicative processes and what cultural work they perform. The study of intermedial relations therefore is highly pertinent for literary studies.

And yet, despite the indisputable significance that media-specific modes of representation and reception and the crossing of media boundaries possess for literary practice, it seems crucial to insist that all versions of a literary text and the different modes of composing, disseminating and engaging with the text that these entail - are part of literary culture. They belong to the medium of literature, no matter to what other medium they may also belong. This may be readily apparent with regard to Clifford's text. We can classify it as digital poetry and posit a hybrid medium in which literature and art blend. ${ }^{4}$ But what about the relation between Clifford's artwork and the YouTube clips? How would we define their common medium and retain a sense of the literary? Rather than construct a variety of hybrid media to account for the diverse ways in which literary texts are written and read in today's media culture, it seems more useful to me to expand our view and to take in the whole variegated media landscape in which literary experience unfolds. As I argued at the beginning of this essay: I think intermedial literary studies will benefit from a change in perspective. Rather than think of intermediality as a relation between distinct media and focus mainly on questions of media change, media borders and media specificity, it would be productive to examine the interrelations between the different medial constellations and practices that built up the literary field. Since literary texts today are written, read, circulated and reworked across a broad variety of media, intermedial literary studies should conceive of literature as a transmedial practice and make it a priority to study the media of literature.

To think of literature as a cultural practice that extends across media boundaries allows us to replace the concept of literature as a self-contained medium with an understanding of literature as a transmedial configuration or network. Although

4 Clifford's The Sweet Old Etcetera indeed not only has been shown at digital art, video and film festivals and exhibitions but also has been included in the second volume of the Electronic Literature Collection (2011). 
it will be the task of another essay to explore the contribution that network theory can make to intermedial literary studies, I would like to point out here that the network offers a model for the conceptualization of reciprocal, recursive and decentralized processes of interaction, exchange and convergence, and of the complex systemic constellations these produce (cf. Schaefer forthcoming). Applied to intermedial literary studies, the network model may help us conceive of media (including literature) as complex structures and dynamic processes that develop through multidirectional, distributed, recursive acts of connection (on the level of technology, signification system, text, communicative process and social framework, for instance). ${ }^{5}$ To comprehend literature as a transmedial configuration or network brings into focus the transformations that literary practice is currently undergoing. It enables us to examine and compare the diverse media formats and contexts in which literature is produced, circulated and experienced today, and to develop an understanding of the literary that is adequate to the digital age because it takes into account the multiplicities and convergences of contemporary media culture.

\section{References}

Bolter, Jay and Richard Grusin. 1999. Remediation. Understanding New Media. Cambridge: MIT Press.

Bray, Joe. 2012. Concrete Poetry and Prose. In The Routledge Companion to Experimental Literature, eds. Joe Bray, Alison Gibbons and Brian McHale, 298-309. London and New York: Routledge.

Clifford, Alison. 2011 [2006]. The Sweet Old Etcetera. In Electronic Literature Collection. Vol. 2. http://collection.eliterature.org/2/works/clifford_sweet_ old_etcetera/sweetweb/index.html. Last accessed 01. 03. 2015.

Clifford, Alison. 2012. The Sweet Old Etcetera. Atticus Review (July 19). http:// atticusreview.org/the-sweet-old-etcetera/. Last accessed 01. 03. 2015.

Conti, Tammy. 2013. One Leaf Falls. http://www.youtube.com/ watch? $v=w R 1 E P 7 z R K d g$. Last accessed 01. 03. 2015.

Cummings, E. E. 1991. Complete Poems. 1904-1962, ed. George J. Firmage. New York: Liveright.

De Biasi, Alex, Leah Lebrow and Sabino Furlone. 2012. I(a. http://www.youtube. com/watch?v=--MOixYJJ9Q. Last accessed 01. 03. 2015.

$5 \quad$ For a poignant application of network theory to the field of adaptation studies, see Regina Schober (2013). 
DiYanni, Robert. 2003. Literature: Approaches to Fiction, Poetry, and Drama. New York: McGraw-Hill.

Friedman, Norman. 1960. e. e. cummings: the art of his poetry. Baltimore: Johns Hopkins.

Funkhouser, Christopher. 2008. Digital Poetry: A Look at Generative, Visual, and Interconnected Possibilities in its First Four Decades. In A Companion to Digital Literary Studies, eds. Susan Schreibman and Ray Siemens, 318-335. Oxford: Blackwell.

Gotera, Vince. 2009. Deconstructing Cummings. http://www.youtube.com/ watch? $v=h X P-7 b y D 7 f o$. Last accessed 01. 03. 2015.

Heusser, Martin. 1995. The Visual Rhetoric of e. e. cummings's 'poempictures.' Word \& Image vol. 11 no. 1 (Jan.-March): 16-30.

Howard, Peter. [n.d.] Flash Poetry. http://tracearchive.ntu.ac.uk/print_article/ index.cfm?article=22. Last accessed 01. 03. 2015.

Kennedy, Richard S. 1980. Dreams in the Mirror: A Biography of E. E. Cummings. New York: Liveright.

Kidder, Rushworth M. 1979. Cummings and Cubism: The Influence of the Visual Arts on Cummings' Early Poetry. Journal of Modern Literature vol. 7 no. 2 (April): 255-291.

Landles, Iain. 2001. An Analysis of Two Poems by E. E. Cummings. SPRING. The Journal of the E. E. Cummings Society vol. 10: 31-43.

lorianngie. 2011. e.e.cummings 1(a. http://www.youtube.com/watch? $v=F 0 F F$ Nk6pNYk. Last accessed 01. 03. 2015.

Lyrez. 2014. The Lyrez Live: A Leaf Falls. http://www.youtube.com/watch?v=gQXsbs3CFA. Last accessed 01. 03. 2015.

Mahler, Andreas. 2010. Performing Arts: "New Aestheticism" and the Media. AAA. Arbeiten aus Anglistik und Amerikanistik vol. 35 no. 1: 102-119.

Morris, Adalaide. 2006. New Media Poetics: As We May Think/How to Write. In New Media Poetics: Contexts, Technotexts, and Theories, eds. Adalaide Morris and Thomas Swiss, 1-46. Cambridge: MIT Press.

Munoz, Jamil. 2006. I(a. http://www.youtube.com/watch?v=okZ0vvPkX6c. Last accessed 01. 03. 2015.

Rowell, Nicholas and Ryan Clavette. 2013. I(a. http://www.youtube.com/ watch?v=um3JxVju7cs. Last accessed 01. 03. 2015.

Rilke, Rainer Maria. 1999. The Essential Rilke. Hopewell, NJ: Ecco Press.

Rajewsky, Irina O. 2005. Intermediality, Intertextuality, and Remediation: A Literary Perspective on Intermediality. Intermédialités vol. 6 (Fall): 43-64. 
ronjosiah. 2007. a leaf falls. http://www.youtube.com/watch?v=82oliOZGDQQ. Last accessed 01.03.2015.

Schaefer, Heike. [forthcoming] The Relevance of Network Theory for the Study of Transcultural Texts. In Network Theory and American Studies, eds. Ulfried Reichardt, Heike Schaefer and Regina Schober, 180-205. Special Issue Amerikastudien / American Studies vol. 60 no. 2.

Schober, Regina. 2013. Adaptation as Connection. Transmediality Reconsidered. In Adaptation Studies. New Challenges, New Directions, eds. Jorgen Bruhn, Anne Gjelsvik and Eirik Frisvold Hanssen, 89-112. London and New York: Bloomsbury.

Seglias, Zesses. 2011. lonesingness. Perf. by Christie Finn. http://www.youtube. com/watch?v=k6DCVNntE-4. Last accessed 01. 03. 2015.

Stevens, John. 2012. E. E. Cummings l (a. http://www.youtube.com/ watch?v=jk1n8u06eoo. Last accessed 01. 03. 2015.

Strehovec, Janez. 2010. Alphabet on the Move. Digital Poetry and the Realm of Language. In Reading Moving Letters: Digital Literature in Research and Teaching, eds. Roberto Simanowski, Jörgen Schäfer and Peter Gendolla, 207227. Bielefeld: transcript Verlag.

Thiery, Louis, Nate Griffin and Parviz Kanga. 2013. [a(1]. http://www.youtube. com/watch?v=m59pCpqGpF4. Last accessed 01. 03. 2015.

\section{List of Figures}

Figure 1. Alison Clifford: The Sweet Old Etcetera (2006)

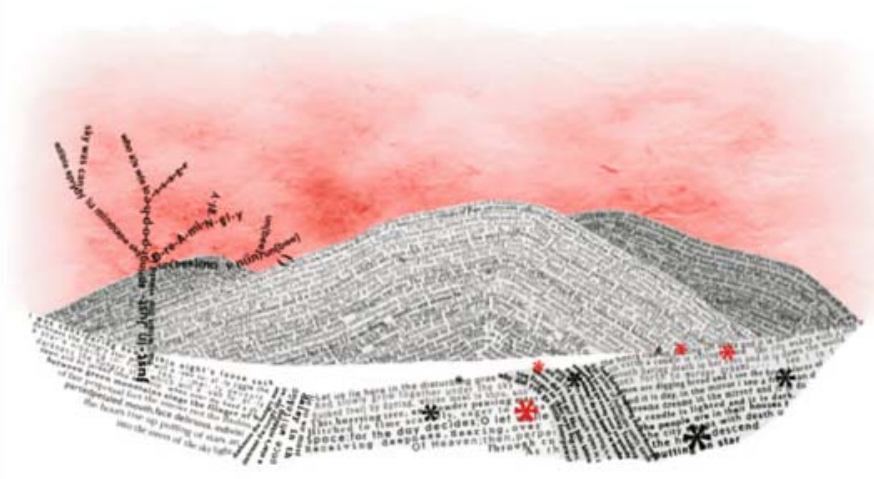


Figure 2. Vince Gotera: Deconstructing Cummings (2009). Figure 3. lorianngie: e.e.cummings 1 (a (2011).
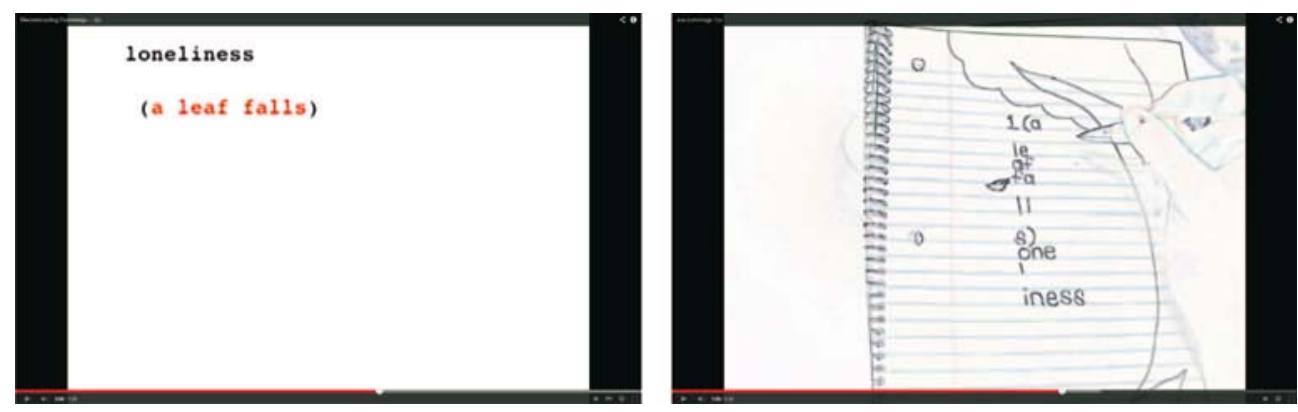